\title{
Approximating common fixed points of total asymptotically nonexpansive mappings in CAT(0) spaces
}

\author{
Hafiz Fukhar-ud-din ${ }^{\mathrm{a}}$, Abdul Rahim Khan ${ }^{\mathrm{a}}$, Nawab Hussain ${ }^{\mathrm{b}, *}$ \\ ${ }^{a}$ Department of Mathematics and Statistics, King Fahd University of Petroleum and Minerals, Dhahran 31261, Saudi Arabia. \\ ${ }^{b}$ Department of Mathematics, King Abdul Aziz University, P. O. Box 80203, Jeddah 21589, Saudi Arabia.
}

Communicated by Z. Kadelburg

\begin{abstract}
We introduce and study convergence of a one-step iterative algorithm for a finite family of total asymptotically nonexpansive mappings on a CAT(0) space. Our results are new in Hilbert spaces as well as CAT(0) spaces; in particular, an analogue of Rhoades weak convergence theorem [B. E. Rhoades, Bull. Austral. Math. Soc., 62 (2000), 307-310] is established both for $\triangle$-convergence and strong convergence in CAT(0) spaces. (C)2017 All rights reserved.
\end{abstract}

Keywords: CAT(0) space, total asymptotically nonexpansive mapping, one-step iterative algorithm, common fixed point, $\triangle$-convergence, strong convergence.

2010 MSC: 47H09, 47H10.

\section{Introduction and preliminaries}

Goebel and Kirk [10] fixed point theorem for an asymptotically nonexpansive mapping on a uniformly convex Banach space remains the only well-known existence result. Thereby, the iterative construction of fixed (common fixed) point of asymptotically nonexpansive type mappings becomes essential on linear as well as nonlinear domain. In this note, we establish convergence results about a one-step iterative algorithm of a finite family of total asymptotically nonexpansive mappings on a nonlinear domain, namely, CAT(0) space.

Let $(X, d)$ be a metric space and $x, y \in X$ with $l=d(x, y)$. A geodesic path from $x$ to $y$ is a mapping $\theta:[0, l] \rightarrow X$ such that $\theta(0)=x, \theta(l)=y$, and $d\left(\theta(t), \theta\left(t^{\prime}\right)\right)=\left|t-t^{\prime}\right|$ for $t, t^{\prime} \in[0, l]$. The image of $\theta$ is known as a geodesic segment in $X$. A metric space $X$ is a uniquely geodesic space if any two points of $X$ are joined by a unique geodesic segment.

A geodesic triangle $\Delta\left(x_{1}, x_{2}, x_{3}\right)$ in a geodesic metric space $X$ consists of three points $x_{1}, x_{2}$, and $x_{3}$ in $X$ and a geodesic segment between each pair of these points. A comparison triangle for geodesic triangle $\Delta\left(x_{1}, x_{2}, x_{3}\right)$ in $X$ is a triangle $\bar{\Delta}\left(x_{1}, x_{2}, x_{3}\right):=\Delta\left(\bar{x}_{1}, \bar{x}_{2}, \bar{x}_{3}\right)$ in $\mathbb{R}^{2}$ such that $d_{\mathbb{R}^{2}}\left(\bar{x}_{i}, \bar{x}_{j}\right)=\mathrm{d}\left(x_{i}, x_{j}\right)$ for all $i, j=1,2,3$.

\footnotetext{
*Corresponding author

Email addresses: hfdin@kf upm.edu.sa (Hafiz Fukhar-ud-din), arahim@kfupm.edu.sa (Abdul Rahim Khan), nhusain@kau. edu. sa (Nawab Hussain)
}

doi:10.22436/jnsa.010.02.37 
A geodesic space $X$ is a $C A T(0)$ space if for each $\Delta$ in $X$ and $\bar{\Delta}$ in $\mathbb{R}^{2}$, the inequality

$$
d(x, y) \leqslant d_{\mathbb{R}^{2}}(\bar{x}, \bar{y})
$$

holds for all $x, y \in \Delta$ and $\bar{x}, \bar{y} \in \bar{\Delta}$.

The Euclidean space $\mathbb{R}^{n}$ equipped with the distance induced by the usual $\ell^{p}$-norm is uniquely geodesic for all $p \in(1, \infty)$ but it is CAT(0) space if and only if $p=2$ (see [5]). All Hilbert spaces are CAT(0) spaces [13] while this is not the case with Banach spaces (cf. [22]).

In this paper, we use the standard notation $(1-\alpha) x \oplus \alpha y$ for the unique point $z$ on the geodesic segment from $x$ to $y$ such that

$$
d(z, x)=\alpha d(x, y) \text { and } d(z, y)=(1-\alpha) d(x, y) .
$$

A subset $C$ of a CAT(0) space is convex if $[x, y]=\{(1-\alpha) x \oplus \alpha y: \alpha \in[0,1]\} \subset C$ for all $x, y \in C$.

Let $\left\{x_{n}\right\}$ be a bounded sequence in a metric space $X$ and $x \in X$. Set

$$
r\left(x,\left\{x_{n}\right\}\right)=\limsup _{n \rightarrow \infty} d\left(x_{n}, x\right) .
$$

The asymptotic radius $r\left(\left\{x_{n}\right\}\right)$ of $\left\{x_{n}\right\}$ is defined by

$$
r\left(\left\{x_{n}\right\}\right)=\inf \left\{r\left(x,\left\{x_{n}\right\}\right): x \in X\right\},
$$

and the asymptotic center $A\left(\left\{x_{n}\right\}\right)$ of $\left\{x_{n}\right\}$ is the set

$$
A\left(\left\{x_{n}\right\}\right)=\left\{x \in X: r\left(x,\left\{x_{n}\right\}\right)=r\left(\left\{x_{n}\right\}\right)\right\} .
$$

A sequence $\left\{x_{n}\right\}$ in $X$ is said to be $\Delta$-convergent to $x \in X$ if $x$ is the unique asymptotic center of every subsequence $\left\{u_{n}\right\}$ of $\left\{x_{n}\right\}$. We write $\Delta-\lim _{n \rightarrow \infty} x_{n}=x$ and call $x$ as $\Delta$-limit of $\left\{x_{n}\right\}$.

Kirk and Panyanak [17] showed that $\Delta$-convergence coincides with weak convergence in Banach spaces satisfying the Opial condition.

Following the definition of $(1-\alpha) x \oplus \alpha y$, we introduce the following notations (see [7]).

For $x_{i} \in X$ and $\alpha_{i} \in[0,1]$ for $i=1,2,3, \ldots, n$ with $\sum_{i=1}^{n} \alpha_{i}=1$, we set

$$
\bigoplus_{i=1}^{2} \alpha_{i} x_{i}=\frac{\alpha_{1}}{\alpha_{1}+\alpha_{2}} x_{1} \oplus \frac{\alpha_{2}}{\alpha_{1}+\alpha_{2}} x_{2}
$$

For $n=3$, we define

$$
\begin{aligned}
\bigoplus_{i=1}^{3} \alpha_{i} x_{i}=\left(1-\alpha_{3}\right) \bigoplus_{i=1}^{2} \alpha_{i} x_{i} \oplus \alpha_{3} x_{3} & =\left(1-\alpha_{3}\right)\left(\frac{\alpha_{1}}{\alpha_{1}+\alpha_{2}} x_{1} \oplus \frac{\alpha_{2}}{\alpha_{1}+\alpha_{2}} x_{2}\right) \oplus \alpha_{3} x_{3} \\
& =\left(1-\alpha_{3}\right)\left(\frac{\alpha_{1}}{1-\alpha_{3}} x_{1} \oplus \frac{\alpha_{2}}{1-\alpha_{3}} x_{2}\right) \oplus \alpha_{3} x_{3} .
\end{aligned}
$$

By induction, we can write

$$
\bigoplus_{i=1}^{n} \alpha_{i} x_{i}=\left(1-\alpha_{n}\right)\left(\frac{\alpha_{1}}{1-\alpha_{n}} x_{1} \oplus \frac{\alpha_{2}}{1-\alpha_{n}} x_{2} \oplus \ldots \oplus \frac{\alpha_{n-1}}{1-\alpha_{n}} x_{n-1}\right) \oplus \alpha_{n} x_{n}
$$

Let $C$ be a nonempty subset of a metric space $X$. A mapping $T: C \rightarrow C$ is:

(i) nonexpansive if

$$
d(T x, T y) \leqslant d(x, y) \text { for all } x, y \in C
$$


(ii) asymptotically nonexpansive mapping if there is a nonnegative real sequence $\left\{\mathbf{c}_{n}\right\}$ such that $c_{n} \rightarrow 0$ and

$$
d\left(T^{n} x, T^{n} y\right) \leqslant\left(1+c_{n}\right) d(x, y) \text { for all } x, y \in C, n \geqslant 1
$$

(iii) generalized asymptotically nonexpansive if there are nonnegative real sequences $\left\{c_{n}\right\}$ and $\left\{d_{n}\right\}$ with $c_{n} \rightarrow 0$ and $d_{n} \rightarrow 0$ such that

$$
d\left(T^{n} x, T^{n} y\right) \leqslant\left(1+c_{n}\right) d(x, y)+d_{n} \text { for all } x, y \in C, n \geqslant 1 ;
$$

(iv) asymptotically nonexpansive in the intermediate sense if it is continuous and the following inequality holds:

$$
\limsup _{n \rightarrow \infty} \sup _{x, y \in C}\left(d\left(T^{n} x, T^{n} y\right)-d(x, y)\right) \leqslant 0 .
$$

It is worth mentioning that the class of asymptotically nonexpansive mappings in the intermediate sense contains properly the class of asymptotically nonexpansive mappings (see, e.g., [16]).

In 2006, Alber et al. [3] introduced: a mapping $T: C \rightarrow C$ is a total asymptotically nonexpansive if there exist nonnegative real sequences $\left\{c_{n}\right\},\left\{d_{n}\right\}$ with $c_{n} \rightarrow 0, d_{n} \rightarrow 0$ and a strictly increasing continuous function $\phi:[0, \infty) \rightarrow[0, \infty)$ with $\phi(0)=0$ satisfying the inequality

$$
d\left(T^{n} x, T^{n} y\right) \leqslant d(x, y)+c_{n} \phi(d(x, y))+d_{n} \text { for all } x, y \in C, n \geqslant 1 .
$$

This is the most general class of mappings which includes all the above mentioned classes (i)-(iv). Remark 1.1. If $\phi(x)=x$ in (1.1), it takes the form

$$
d\left(T^{n} x, T^{n} y\right) \leqslant\left(1+c_{n}\right) d(x, y)+d_{n} \text { for all } x, y \in C, n \geqslant 1,
$$

and so $T$ is a generalized asymptotically nonexpansive mapping. In addition, if $d_{n}=0$, it becomes asymptotically nonexpansive. If $c_{n}=0=d_{n}$ for all $n \geqslant 1$ in (1.1), it reduces to a nonexpansive mapping. Denote by $F(T)$, the set of fixed points of $T$, choose $c_{n}=0=d_{n}$ for all $n \geqslant 1$ and $y \in F(T)$ in (1.1), it becomes quasi-nonexpansive.

Mann [18] introduced an iterative algorithm to approximate fixed point of a nonexpansive mapping on a Banach space. Later on, it was observed that Mann iterative algorithm does not converge to a fixed point of pseudocontractive mappings and this led to the introduction of Ishikawa iterative algorithm [12]. Many authors (see for example, $[2,21]$ ) have studied Ishikawa iterative algorithm for one mapping and two mappings. Its further extension to a finite family of nonlinear mappings on Banach spaces and CAT(0) spaces has been considered in [14, 19] (see also, [4, 11, 15]).

If $I=\{1,2,3, \ldots, m\}$, a one-step iterative algorithm for a finite family $\left\{T_{i}: i \in I\right\}$ of total asymptotically nonexpansive mappings in a CAT(0) space is defined as follows:

For an arbitrary $x_{1} \in C$, we define the iterative sequence $\left\{x_{n}\right\}$ in $C$ as follows:

$$
x_{n+1}=\bigoplus_{i=0}^{m} a_{n, i} T_{i}^{n} x_{n}
$$

where $T_{0}=I$ (the identity mapping) and $\left\{a_{n, i}\right\}$ are $(m+1)$ sequences in $[0,1]$ such that $\sum_{i=0}^{m} a_{n, i}=1$.

If $a_{n, i}=0$ for $i \geqslant 2$ or $T_{i}^{n}=T^{n}$ for each $i \geqslant 1$ in (1.2), then it becomes Mann iterative algorithm in a CAT(0) space. To know more about the recent developments for the class of asymptotically nonexpansive and total asymptotically nonexpansive mappings, we refer the reader to [8].

We need the following lemmas for our convergence analysis.

Lemma 1.2 ([21]). If $\left\{r_{n}\right\},\left\{s_{n}\right\}$, and $\left\{t_{n}\right\}$ are nonnegative real sequences satisfying

$$
r_{n+1} \leqslant\left(1+s_{n}\right) r_{n}+t_{n} \text { for all } n \geqslant 1, \sum_{n=1}^{\infty} s_{n}<\infty \text { and } \sum_{n=1}^{\infty} t_{n}<\infty,
$$

then $\lim _{n \rightarrow \infty} r_{n}$ exists. 
Lemma 1.3 ([7]). Let $X$ be a CAT(0) space with $x, x_{i} \in X$ and $\alpha_{i} \in[0,1]$ for $i=1,2,3, \ldots, n$ such that $\sum_{i=1}^{n} \alpha_{i}=$ 1. Then, $d\left(\bigoplus_{i=1}^{n} \alpha_{i} x_{i}, x\right) \leqslant \sum_{i=1}^{n} \alpha_{i} d\left(x_{i}, x\right)$.

Lemma 1.4 ([6]). Let $X$ be a CAT(0) space with $x, x_{i} \in X$ and $\alpha_{i} \in[0,1]$ for $i=1,2,3, \ldots, n$ such that $\sum_{i=1}^{n} \alpha_{i}=$ 1. Then

$$
d\left(\bigoplus_{i=1}^{n} \alpha_{i} x_{i}, x\right)^{2} \leqslant \sum_{i=1}^{n} \alpha_{i} d\left(x_{i}, x\right)^{2}-\sum_{i, j=1, i \neq j}^{n} \alpha_{i} \alpha_{j} d\left(x_{i}, x_{j}\right)^{2} .
$$

Lemma 1.5 ([8]). If $\mathrm{C}$ is a closed and convex subset of a complete CAT $(0)$ space and $\left\{x_{n}\right\}$ is a bounded sequence in $\mathrm{C}$, then the asymptotic center of $\left\{\mathrm{x}_{\mathrm{n}}\right\}$ is unique and lies in $\mathrm{C}$.

Lemma 1.6 ([9]). Let $\mathrm{C}$ be a nonempty closed and convex subset of a complete $\mathrm{CAT}(0)$ space. Let $\left\{\mathrm{x}_{\mathrm{n}}\right\}$ be a bounded sequence in $C$ such that $A_{C}\left(\left\{x_{n}\right\}\right)=\{y\}$ and $r\left(\left\{x_{n}\right\}\right)=\rho$. If $\left\{y_{m}\right\}$ is another sequence in $C$ such that $\lim _{\mathfrak{m} \rightarrow \infty} r\left(y_{\mathfrak{m}},\left\{x_{\mathfrak{n}}\right\}\right)=\rho$ (a real number), then $\lim _{\mathfrak{m} \rightarrow \infty} y_{\mathfrak{m}}=y$.

\section{Convergence analysis}

From now onwards, we assume that $F=\bigcap_{i \in I} F\left(T_{i}\right) \neq \phi$ for a finite family $\left\{T_{i}: i \in I\right\}$ of total asymptotically nonexpansive mappings.

We start with the following technical result.

Lemma 2.1. Let $\mathrm{C}$ be a nonempty closed and convex subset of a $\mathrm{CAT}(0)$ space $\mathrm{X}$ and $\left\{\mathrm{T}_{i}: i \in \mathrm{I}\right\}$ be a finite family of total asymptotically nonexpansive mappings where sequences $\left\{\mathrm{c}_{\mathrm{n}, \mathrm{i}}\right\},\left\{\mathrm{d}_{\mathrm{n}, \mathrm{i}}\right\}$, and functions $\phi_{i}$ satisfy the following conditions:

(C1): $\sum_{n=1}^{\infty} c_{n, i}<\infty$ and $\sum_{n=1}^{\infty} d_{n, i}<\infty$;

(C2): there exist constants $\alpha_{i}, \beta_{i}>0$ such that $\phi_{i}(t) \leqslant \alpha_{i} t$ for all $t \geqslant \beta_{i}$.

If $\left\{x_{n}\right\}$ is the sequence in (1.2), with $T_{0}=I$ (the identity mapping) and $a_{n, i} \in[0,1]$ such that $\sum_{i=1}^{m+1} a_{n, i}=1$, then $\lim _{n \rightarrow \infty} d\left(x_{n}, x\right)$ exists for all $p \in F$.

Proof. By (C2) and strictly increasingness of $\phi_{i}$, it follows that

$$
\phi_{i}(t) \leqslant \phi_{i}\left(\beta_{i}\right)+\alpha_{i} t \text { for } i \in I .
$$

For any $p \in F$, we apply Lemma 1.3 to the iterative algorithm (1.2) and use (2.1) to get

$$
\begin{aligned}
d\left(x_{n+1}, p\right) & =d\left(\bigoplus_{i=0}^{m} a_{n, i} T_{i}^{n} x_{n}, p\right) \\
& \leqslant a_{n, 0} d\left(x_{n}, p\right)+\sum_{i=1}^{m} a_{n, i} d\left(T_{i}^{n} x_{n}, p\right) \\
& \leqslant a_{n, 0} d\left(x_{n}, p\right)+\sum_{i=1}^{m} a_{n, i}\left[d\left(x_{n}, p\right)+c_{n, i} \phi_{i}\left(d\left(x_{n}, p\right)\right)+d_{n, i}\right] \\
& \leqslant a_{n, 0} d\left(x_{n}, p\right)+\sum_{i=1}^{m} a_{n, i}\left[\begin{array}{c}
d\left(x_{n}, p\right)+c_{n, i} \phi_{i}\left(\beta_{i}\right) \\
\left.+c_{n, i} \alpha_{i} d\left(x_{n}, p\right)+d_{n, i}\right] \\
\end{array}=a_{n, 0} d\left(x_{n}, p\right)+\sum_{i=1}^{m} a_{n, i}\left[\left(1+c_{n, i} \alpha_{i}\right) d\left(x_{n}, p\right)+c_{n, i} \phi_{i}\left(\beta_{i}\right)+d_{n, i}\right]\right. \\
& =\left(1+\sum_{i=1}^{m} a_{n, i} c_{n, i} \alpha_{i}\right) d\left(x_{n}, p\right)+\sum_{i=1}^{m} a_{n, i} c_{n, i} \phi_{i}\left(\beta_{i}\right)+\sum_{i=1}^{m} a_{n, i} d_{n, i}
\end{aligned}
$$




$$
\leqslant\left(1+\alpha \delta \sum_{i=1}^{m} c_{n, i}\right) d\left(x_{n}, p\right)+\alpha \delta \sum_{i=1}^{m} c_{n, i}+\delta \sum_{i=1}^{m} d_{n, i}
$$

where $\alpha=\max _{1 \leqslant i \leqslant m}\left(\alpha_{i}, \phi_{i}\left(\beta_{i}\right)\right)$. That is,

$$
d\left(x_{n+1}, p\right) \leqslant\left(1+\alpha(1-\delta) \sum_{i=1}^{m} c_{n, i}\right) d\left(x_{n}, p\right)+(1-\delta)\left(\alpha \sum_{i=1}^{m} c_{n, i}+\sum_{i=1}^{m} d_{n, i}\right) .
$$

Now Lemma 1.2 applied to (2.2) implies that $\lim _{n \rightarrow \infty} d\left(x_{n}, p\right)$ exists.

Lemma 2.2. Let $\mathrm{C}, X,\left\{\mathrm{~T}_{i}: i \in \mathrm{I}\right\},(\mathrm{C} 1)$, and (C2) be as in Lemma 2.1. If $\left\{\mathrm{T}_{i}: i \in \mathrm{I}\right\}$ is uniformly continuous, then $\lim _{n \rightarrow \infty} d\left(x_{n}, T_{i} x_{n}\right)=0$ for $i \in I$.

Proof. For any $p \in F$, we apply Lemma 1.4 to (1.2) and utilize (2.1) to get

$$
\begin{aligned}
d\left(x_{n+1}, p\right)^{2}= & d\left(\bigoplus_{i=0}^{m} a_{n, i} T_{i}^{n} x_{n}, p\right)^{2} \\
\leqslant & a_{n, 0} d\left(x_{n}, p\right)^{2}+\sum_{i=1}^{m} a_{n, i} d\left(T_{i}^{n} x_{n}, p\right)^{2}-\sum_{i=1}^{m} a_{n, 1} a_{n, i} d\left(x_{n}, T_{i}^{n} x_{n}\right)^{2} \\
\leqslant & a_{n, 0} d\left(x_{n}, p\right)^{2}+\sum_{i=1}^{m} a_{n, i}\left[\left(1+c_{n, i} \alpha_{i}\right) d\left(x_{n}, p\right)+c_{n, i} \phi_{i}\left(\beta_{i}\right)+d_{n, i}\right]^{2} \\
& -\sum_{i=1}^{m} a_{n, 1} a_{n, i} d\left(x_{n}, T_{i}^{n} x_{n}\right)^{2} \\
\leqslant & a_{n, 0} d\left(x_{n}, p\right)^{2}+\sum_{i=1}^{m} a_{n, i}\left[\begin{array}{c}
\left(1+c_{n, i} \alpha_{i}\right)^{2} d\left(x_{n}, p\right)^{2}+\left(c_{n, i} \phi_{i}\left(\beta_{i}\right)+d_{n, i}\right)^{2} \\
+2\left(1+c_{n, i} \alpha_{i}\right) d\left(x_{n}, p\right)\left(c_{n, i} \phi_{i}\left(\beta_{i}\right)+d_{n, i}\right)
\end{array}\right] \\
& -\sum_{i=1}^{m} a_{n, 1} a_{n, i} d\left(x_{n}, T_{i}^{n} x_{n}\right)^{2} \\
\leqslant & d\left(x_{n}, p\right)^{2}+\sum_{i=1}^{m} a_{n, i}\left[\begin{array}{c}
\left.\left(c_{n, i}^{2} \alpha_{i}^{2}+2 c_{n, i} \alpha_{i}\right) d\left(x_{n}, p\right)^{2}+\left(c_{n, i} \phi_{i}\left(\beta_{i}\right)+d_{n, i}\right)^{2}\right] \\
+2\left(1+c_{n, i} \alpha_{i}\right) d\left(x_{n}, p\right)\left(c_{n, i} \phi_{i}\left(\beta_{i}\right)+d_{n, i}\right)
\end{array}\right] \\
& -\sum_{i=1}^{m} a_{n, 1} a_{n, i} d\left(x_{n}, T_{i}^{n} x_{n}\right)^{2} .
\end{aligned}
$$

Since $\left\{d\left(x_{n}, p\right)\right\},\left\{c_{n, i}\right\}$, and $\left\{d_{n, i}\right\}$ are bounded sequences, we can fix $M>0$ such that

$$
\begin{aligned}
& \left(c_{n, i}^{2} \alpha_{i}^{2}+2 c_{n, i} \alpha_{i}\right) d\left(x_{n}, p\right)^{2}+\left(c_{n, i} \phi_{i}\left(\beta_{i}\right)+d_{n, i}\right)^{2}+2\left(1+c_{n, i} \alpha_{i}\right) d\left(x_{n}, p\right)\left(c_{n, i} \phi_{i}\left(\beta_{i}\right)+d_{n, i}\right) \\
& \quad=M\left(c_{n, i}+d_{n, i}\right) .
\end{aligned}
$$

That is,

$$
\delta^{2} \sum_{i=1}^{m} d\left(x_{n}, T_{i} x_{n}\right)^{2} \leqslant d\left(x_{n}, p\right)^{2}-d\left(x_{n+1}, p\right)^{2}+\sum_{i=1}^{m+1} M a_{n, i}\left(c_{n, i}+d_{n, i}\right) .
$$

It follows that for any positive integer $N \geqslant 1$,

$$
\begin{aligned}
\delta^{2} \sum_{n=1}^{N} \sum_{i=1}^{m} d\left(x_{n}, T_{i} x_{n}\right)^{2} & \leqslant d\left(x_{1}, p\right)^{2}-d\left(x_{N+1}, p\right)^{2}+\delta M \sum_{i=1}^{m+1} \sum_{n=1}^{N}\left(c_{n, i}+d_{n, i}\right) \\
& \leqslant d\left(x_{1}, p\right)^{2}+\delta M \sum_{i=1}^{m+1} \sum_{n=1}^{N}\left(c_{n, i}+d_{n, i}\right) .
\end{aligned}
$$


That is,

$$
\delta^{2} \sum_{n=1}^{N} \sum_{i=1}^{m} d\left(x_{n}, T_{i}^{n} x_{n}\right)^{2}<d\left(x_{1}, p\right)^{2}+\delta M \sum_{i=1}^{m+1} \sum_{n=1}^{N}\left(c_{n, i}+d_{n, i}\right) .
$$

When $N \rightarrow \infty$ in (2.3), we get that $\delta^{2} \sum_{n=1}^{\infty} \sum_{i=1}^{m} d\left(x_{n}, T_{i}^{n} x_{n}\right)^{2}<\infty$ and hence

$$
\lim _{n \rightarrow \infty} \sum_{i=1}^{m} d\left(x_{n}, T_{i}^{n} x_{n}\right)^{2}=0
$$

Therefore,

$$
\lim _{n \rightarrow \infty} d\left(x_{n}, T_{i}^{n} x_{n}\right)=0 \text { for } i=1,2,3, \ldots, m \text {. }
$$

Now we show that $\lim _{n \rightarrow \infty} d\left(x_{n}, T_{i} x_{n}\right)=0$ for each $i=1,2,3, \ldots, m$. Since

$$
d\left(x_{n}, x_{n+1}\right)=d\left(x_{n}, \bigoplus_{i=0}^{m} a_{n, i} T_{i}^{n} x_{n}\right) \leqslant \sum_{i=0}^{m} a_{n, i} d\left(x_{n}, T_{i}^{n} x_{n}\right),
$$

and (2.4) hold, therefore we get

$$
\lim _{n \rightarrow \infty} d\left(x_{n}, x_{n+1}\right)=0
$$

The inequality

$$
d\left(x_{n}, T_{i} x_{n}\right) \leqslant d\left(x_{n}, x_{n+1}\right)+d\left(x_{n+1}, T_{i}^{n+1} x_{n+1}\right)+d\left(T_{i}^{n+1} x_{n+1}, T_{i}^{n+1} x_{n}\right)+d\left(T_{i}^{n+1} x_{n}, T_{i} x_{n}\right),
$$

uniformly continuity of $T_{i}$, and (2.5) imply that

$$
\lim _{n \rightarrow \infty} d\left(x_{n}, T_{i} x_{n}\right)=0 \text { for } i \in I
$$

Next we obtain our $\triangle$-convergence result.

Theorem 2.3. Let $\mathrm{C}, \mathrm{X},\left\{\mathrm{T}_{\mathrm{i}}: i \in \mathrm{I}\right\},(\mathrm{C} 1)$, and (C2) be as in Lemma 2.2. If $\mathrm{X}$ is complete and $\left\{\mathrm{x}_{\mathrm{n}}\right\}$ is the sequence in (1.2), where $\mathrm{T}_{0}=\mathrm{I}$ (the identity mapping) and $\mathrm{a}_{\mathrm{n}, \mathrm{i}} \in[\delta, 1-\delta]$ for some $\delta \in\left(0, \frac{1}{2}\right)$ with $\sum_{i=0}^{m} a_{n, i}=1$, then $\left\{x_{n}\right\} \triangle$-converges to a point in $\mathrm{F}$.

Proof. The sequence $\left\{x_{n}\right\}$ is bounded (cf. Lemma 2.1). Hence by Lemma 1.5, $\left\{x_{n}\right\}$ has a unique asymptotic center, that is, $A_{C}\left(\left\{x_{n}\right\}\right)=\{x\}$. If $\left\{u_{n}\right\}$ is any subsequence of $\left\{x_{n}\right\}$, then again by Lemma 1.5, we have $A_{C}\left(\left\{u_{n}\right\}\right)=\{u\}$ and so (2.6) gives that

$$
\lim _{n \rightarrow \infty} d\left(u_{n}, T_{i} u_{n}\right)=0 \text { for } i=1,2,3, \ldots, m .
$$

We show that $u \in F$. Define a sequence $\left\{z_{i}\right\}$ in $C$ by $z_{i}=T_{1}^{i} u$. By the property of $\phi_{1}$ and (C2), we get the following estimate

$$
\begin{aligned}
d\left(z_{i}, u_{n}\right) & \leqslant d\left(T_{1}^{i} u, T_{1}^{i} u_{n}\right)+d\left(T_{1}^{i} u_{n}, T_{1}^{i-1} u_{n}\right)+\cdots+d\left(T_{1} u_{n}, u_{n}\right) \\
& \leqslant d\left(u, u_{n}\right)+c_{n, 1} \phi_{1}\left(d\left(u, u_{n}\right)\right)+d_{n, 1}+\sum_{r=0}^{i-1} d\left(T_{1}^{r} u_{n}, T_{1}^{r+1} u_{n}\right) \\
& \leqslant\left(1+c_{n, 1} \alpha\right) d\left(u, u_{n}\right)+c_{n, 1} \phi_{1}(\beta)+d_{n, 1}+\sum_{r=0}^{i-1} d\left(T_{1}^{r} u_{n}, T_{1}^{r+1} u_{n}\right) .
\end{aligned}
$$


Taking limsup $\operatorname{sun}_{n \rightarrow \infty}$ on both sides of the above estimate, applying uniform continuity of $\mathrm{T}_{1}$ and using (2.7), we have that

$$
r\left(z_{i},\left\{u_{n}\right\}\right)=\limsup _{n \rightarrow \infty} d\left(z_{i}, u_{n}\right) \leqslant \limsup _{n \rightarrow \infty} d\left(u, u_{n}\right)=r\left(u,\left\{u_{n}\right\}\right) .
$$

That is, $\left|r\left(z_{i},\left\{u_{n}\right\}\right)-r\left(u,\left\{u_{n}\right\}\right)\right| \rightarrow 0$ as $i \rightarrow \infty$. It follows from Lemma 1.6 that $\lim _{i \rightarrow \infty} T_{1}^{i} u=u$. Again, utilizing the uniform continuity of $T_{1}$, we have that $T_{1}(u)=T_{1}\left(\lim _{i \rightarrow \infty}^{i} T_{1} u\right)=\lim _{i \rightarrow \infty} T_{1}^{i+1} u=u$. Similarly, we can show that $T_{i}(u)=u$ for $i=2,3,4, \ldots, m$. Therefore $u \in F$. If $x \neq u$, then the uniqueness of the asymptotic centers implies the following contradiction:

$$
\limsup _{n \rightarrow \infty} d\left(u_{n}, u\right)<\limsup _{n \rightarrow \infty} d\left(u_{n}, x\right) \leqslant \limsup _{n \rightarrow \infty} d\left(x_{n}, x\right)<\limsup _{n \rightarrow \infty} d\left(x_{n}, u\right)=\limsup _{n \rightarrow \infty} d\left(u_{n}, u\right) .
$$

Hence $x=u$. This proves that $u$ is the unique asymptotic center of $\left\{u_{n}\right\}$ for every subsequence $\left\{u_{n}\right\}$ of $\left\{x_{n}\right\}$.

Let $C$ be a nonempty subset of a metric space $X$. A family of mappings $T_{i}: C \rightarrow C(i=1,2,3, \ldots, m)$ with a nonempty common fixed point set $F$ in $C$ is said to satisfy condition (AR) if there is a nondecreasing function $g:[0, \infty) \rightarrow[0, \infty)$ with $g(0)=0$ and $g(r)>0$ for $r>0$ and $\lambda_{i} \in[0,1]$ with $\sum_{i=1}^{n} \lambda_{i}=1$ such that

$$
\sum_{i=1}^{n} \lambda_{i} d\left(x, T_{i} x\right) \geqslant g(d(x, F))
$$

where $d(x, F)=\inf _{p \in F} d(x, p)$ for all $x \in C$.

The condition (AR) reduces to condition $(A)[20]$ if $T_{i}=T$ for $i=1,2,3, \ldots, m$. We shall use condition $(A R)$ instead of demicompactness of the mappings [20] for strong convergence of $\left\{x_{n}\right\}$ in (1.2).

Theorem 2.4. Let $\mathrm{C}$ be a nonempty closed and convex subset of a CAT(0) space $\mathrm{X}$ and $\left\{\mathrm{T}_{\mathrm{i}}: i \in \mathrm{I}\right\}$ be a finite family of total asymptotically nonexpansive mappings satisfying condition (AR) where the sequences $\left\{\mathrm{c}_{n, i}\right\},\left\{\mathrm{d}_{\mathrm{n}, \mathrm{i}}\right\}$ and functions $\phi_{i}$ satisfy the conditions (C1) and (C2). If $\left\{x_{n}\right\}$ is the sequence in (1.2), where $\mathrm{T}_{0}=\mathrm{I}$ (the identity mapping) and $a_{n, i} \in[\delta, 1-\delta]$ for some $\delta \in\left(0, \frac{1}{2}\right)$ with $\sum_{i=0}^{m} a_{n, i}=1$, then $\left\{x_{n}\right\}$ converges strongly to a point in F.

Proof. Set $s_{n}=\alpha(1-\delta) \sum_{i=1}^{m} c_{n, i}$ and $t_{n}=(1-\delta)\left(\alpha \sum_{i=1}^{m} c_{n, i}+\sum_{i=1}^{m} d_{n, i}\right)$. Obviously, $\sum_{n=1}^{\infty} s_{n}<\infty$ and $\sum_{n=1}^{\infty} t_{n}<\infty$.

By taking $\inf _{\mathfrak{p} \in \mathrm{F}}$ on both sides of (2.2), we obtain that

$$
d\left(x_{n+1}, F\right) \leqslant\left(1+s_{n}\right) d\left(x_{n}, F\right)+t_{n} .
$$

As a consequence of Lemma 1.2 and (2.8), we get that $\lim _{n \rightarrow \infty} d\left(x_{n}, F\right)$ exists.

Now by the condition (AR), we get

$$
\lim _{n \rightarrow \infty} g\left(d\left(x_{n}, F\right)\right) \leqslant \sum_{i=1}^{m} a_{n, i} \lim _{n \rightarrow \infty} d\left(x_{n}, T_{i} x_{n}\right)=0 .
$$

Since $g$ is a nondecreasing function and $g(0)=0$, therefore $\lim _{n \rightarrow \infty} d\left(x_{n}, F\right)=0$. Next, we claim that $\left\{x_{n}\right\}$ is a Cauchy sequence. Assume that $\sum_{n=1}^{\infty} s_{n}=s$ and hence $\prod_{n=1}^{\infty}\left(1+s_{n}\right)=s$. For $\varepsilon>0$, there exists $n_{0} \geqslant 1$ such that $d\left(x_{n_{0}}, F\right)<\frac{\varepsilon}{4 s+4}$ and $\sum_{n=n_{0}}^{\infty} t_{n}<\frac{\varepsilon}{4 s}$.

Let $m>n \geqslant n_{0}$ and $p \in F$. With the help of (2.8), we obtain

$$
\begin{aligned}
d\left(x_{m}, x_{n}\right) & \leqslant d\left(x_{m}, F\right)+d\left(x_{n}, F\right) \\
& \leqslant \prod_{i=n_{0}}^{m-1}\left(1+s_{i}\right) d\left(x_{n_{0}}, F\right)+\prod_{i=n_{0}}^{m-1}\left(1+s_{i}\right) \sum_{n=n_{0}}^{m-1} t_{i}+\prod_{i=n_{0}}^{n-1}\left(1+s_{i}\right) d\left(x_{n_{0}}, F\right)+\prod_{i=n_{0}}^{n-1}\left(1+s_{i}\right) \sum_{n=n_{0}}^{n-1} t_{i}
\end{aligned}
$$




$$
\begin{aligned}
& \leqslant \prod_{i=n_{0}}^{\infty}\left(1+s_{i}\right) d\left(x_{n_{0}}, F\right)+\prod_{i=n_{0}}^{\infty}\left(1+s_{i}\right) \sum_{n=n_{0}}^{\infty} t_{i}+\prod_{i=n_{0}}^{\infty}\left(1+s_{i}\right) d\left(x_{n_{0}}, F\right)+\prod_{i=n_{0}}^{\infty}\left(1+s_{i}\right) \sum_{n=n_{0}}^{\infty} t_{i} \\
& <2\left[(1+s) \frac{\varepsilon}{4 s+4}+s \frac{\varepsilon}{4 s}\right]=\varepsilon .
\end{aligned}
$$

This proves that $\left\{x_{n}\right\}$ is a Cauchy sequence in C. Let $\lim _{n \rightarrow \infty} x_{n}=q$. Then $d(q, F)=d\left(\lim _{n \rightarrow \infty} x_{n}, F\right)=$ $\lim _{n \rightarrow \infty} d\left(x_{n}, F\right)=0$. As $F$ is closed, so we obtain $q \in F$. Hence $\left\{x_{n}\right\}$ strongly converges to a point of $F$.

Since every Hilbert space is a CAT(0) space and Definitions (i)-(iv) are special case of (1.1), therefore the following results can be seen as a corollary of our results.

Corollary 2.5. Let $\mathrm{C}$ be a nonempty closed and convex subset of a Hilbert space $\mathrm{H}$ and $\left\{\mathrm{T}_{i}: i \in \mathrm{I}\right\}$ be a finite family of uniformly continuous and total asymptotically nonexpansive mappings, where sequences $\left\{c_{n, i}\right\},\left\{d_{n, i}\right\}$, and functions $\phi_{i}$ satisfy the conditions (C1) and (C2). If $\left\{x_{n}\right\}$ is the sequence defined by $x_{1} \in C: x_{n+1}=$ $\sum_{i=0}^{m} a_{n, i} T_{i}^{n} x_{n}$, where $T_{0}=I$ (the identity mapping) and $a_{n, i} \in[\delta, 1-\delta]$ for some $\delta \in\left(0, \frac{1}{2}\right)$ with $\sum_{i=0}^{m} a_{n, i}=$ 1 , then $\left\{x_{n}\right\}$ converges weakly to a point in $\mathrm{F}$.

Corollary 2.6. Let $\mathrm{C}$ be a nonempty closed and convex subset of a Hilbert space $\mathrm{H}$ and $\left\{\mathrm{T}_{\mathrm{i}}: \mathrm{i} \in \mathrm{I}\right\}$ be a finite family of total asymptotically nonexpansive mappings satisfying the condition (AR) where the sequences $\left\{\mathbf{c}_{n, i}\right\}$, $\left\{\mathrm{d}_{n, i}\right\}$, and functions $\phi_{i}$ satisfy the conditions (C1) and (C2). If $\left\{x_{n}\right\}$ is the sequence defined by $x_{1} \in C: x_{n+1}=$ $\sum_{i=0}^{m} a_{n, i} T_{i}^{n} x_{n}$, where $T_{0}=I$ (the identity mapping) and $a_{n, i} \in[\delta, 1-\delta]$ for some $\delta \in\left(0, \frac{1}{2}\right)$ with $\sum_{i=0}^{m} a_{n, i}=$ 1 , then $\left\{x_{n}\right\}$ converges strongly to a point in $F$.

Corollary 2.7. Let $\mathrm{C}$ be a nonempty closed and convex subset of a CAT(0) space $\mathrm{X}$ and $\left\{\mathrm{T}_{i}: i \in \mathrm{I}\right\}$ be a finite family of uniformly continuous and asymptotically nonexpansive mappings in the intermediate sense with sequences $\left\{\mathbf{c}_{n, i}\right\}$ such that $\sum_{n=1}^{\infty} c_{n, i}<\infty$. If $\left\{x_{n}\right\}$ is the sequence defined by $x_{1} \in C: x_{n+1}=\bigoplus_{i=0}^{m} a_{n, i} T_{i}^{n} x_{n}$, where $T_{0}=I$ (the identity mapping) and $a_{n, i} \in[\delta, 1-\delta]$ for some $\delta \in\left(0, \frac{1}{2}\right)$ with $\sum_{i=0}^{m} a_{n, i}=1$, then $\left\{x_{n}\right\} \triangle$-converges to a point in $\mathrm{F}$.

Corollary 2.8. Let $\mathrm{C}$ be a nonempty closed and convex subset of a CAT(0) space $X$ and $\left\{T_{i}: i \in I\right\}$ be a finite family of uniformly continuous and asymptotically nonexpansive mappings in the intermediate sense satisfying condition (AR) with sequences $\left\{c_{n, i}\right\}$ such that $\sum_{n=1}^{\infty} c_{n, i}<\infty$. If $\left\{x_{n}\right\}$ is the sequence defined by $x_{1} \in C$ : $x_{n+1}=\bigoplus_{i=0}^{m} a_{n, i} T_{i}^{n} x_{n}$, where $T_{0}=I$ (the identity mapping) and $a_{n, i} \in[\delta, 1-\delta]$ for some $\delta \in\left(0, \frac{1}{2}\right)$ with $\sum_{i=0}^{m} a_{n, i}=1$, then $\left\{x_{n}\right\}$ converges strongly to a point in $\mathrm{F}$.

Remark 2.9. We observe that:

1) The results of Abbas et al. [2] in Banach spaces depend on the condition $d\left(x, S^{n} x\right) \leqslant d\left(S^{n} x, T^{n} x\right)$ on two asymptotically nonexpansive mappings $S$ and $T$, whereas we do not need such type of condition for the larger class of total asymptotically nonexpansive mappings in CAT(0) spaces.

2) One can easily establish results of this paper for nonself total asymptotically nonexpansive mappings. Hence the new results will be analogue of the results of Zhou et al. [23] in CAT(0) spaces for nonself total asymptotically nonexpansive mappings.

3) Corollary 2.7 (resp. Corollary 2.8) generalizes Theorem 2.2 (resp. Theorem 2.4) in [1] for a finite family of asymptotically nonexpansive mappings in the intermediate sense.

4) Theorems 2.3 and 2.4 are $\triangle$-convergence and strong convergence analogue of weak convergence Theorem of Rhoades [19].

Open Problem: Devise an iterative algorithm in CAT(0) spaces for approximating common fixed point of an infinite family of total asymptotically nonexpansive mappings.

\section{Acknowledgment}

The author H. Fukhar-ud-din would like to acknowledge the support provided by the Deanship of Scientific Research(DSR) at King Fahd University of Petroleum \& Minerals (KFUPM) for funding thiswork 
through project No. IN151014. The authors A. R. Khan and N. Hussain acknowledge gratefully KACST, Riyad, Saudi Arabia, for supporting Research Project ARP-32-34.

\section{References}

[1] M. Abbas, S. H. Khan, Some $\Delta$-convergence theorems in CAT(0) spaces, Hacet. J. Math. Stat., 40 (2011), 563-569. 3

[2] M. Abbas, S. H. Khan, J. K. Kim, A new one-step iterative process for common fixed points in Banach spaces, J. Inequal. Appl., 2008 (2008), 10 pages. 1, 1

[3] Y. I. Alber, C. E. Chidume, H. Zegeye, Approximating fixed points of total asymptotically nonexpansive mappings, Fixed Point Theory Appl., 2006 (2006), 20 pages. 1

[4] A. Alotaibi, V. Kumar, N. Hussain, Convergence comparison and stability of Jungck-Kirk-type algorithms for common fixed point problems, Fixed Point Theory Appl., 2013 (2013), 30 pages. 1

[5] M. R. Bridson, A. Haefliger, Metric spaces of non-positive curvature, Grundlehren der Mathematischen Wissenschaften [Fundamental Principles of Mathematical Sciences], Springer-Verlag, Berlin, (1999). 1

[6] C. E. Chidume, A. U. Bello, P. Ndambomve, Strong and $\Delta$-convergence theorems for common fixed points of a finite family of multivalued demicontractive mappings in CAT(0) spaces, Abstr. Appl. Anal., 2014 (2014), 6 pages. 1.4

[7] S. Dhompongsa, A. Kaewkhao, B. Panyanak, On Kirk's strong convergence theorem for multivalued nonexpansive mappings on CAT(0) spaces, Nonlinear Anal., 75 (2012), 459-468. 1, 1.3

[8] S. Dhompongsa, B. Panyanak, On $\Delta$-convergence theorems in CAT(0) spaces, Comput. Math. Appl., 56 (2008), $2572-$ 2579. 1, 1.5

[9] H. Fukhar-ud-din, Existence and approximation of fixed points in convex metric spaces, Carpathian J. Math., 30 (2014), 175-185. 1.6

[10] K. Goebel, W. A. Kirk, A fixed point theorem for asymptotically nonexpansive mappings, Proc. Amer. Math. Soc., 35 (1972), 171-174. 1

[11] N. Hussain, W. Takahashi, Weak and strong convergence theorems for semigroups of mappings without continuity in Hilbert spaces, J. Nonlinear Convex Anal., 14 (2013), 769-783. 1

[12] S. Ishikawa, Fixed points by a new iteration method, Proc. Amer. Math. Soc., 44 (1974), 147-150. 1

[13] M. A. Khamsi, A. R. Khan, Inequalities in metric spaces with applications, Nonlinear Anal., 74 (2011), 4036-4045. 1

[14] A. R. Khan, M. A. Khamsi, H. Fukhar-ud-din, Strong convergence of a general iteration scheme in CAT (0) spaces, Nonlinear Anal., 74 (2011), 783-791. 1

[15] A. R. Khan, V. Kumar, N. Hussain, Analytical and numerical treatment of Jungck-type iterative schemes, Appl. Math. Comput., 231 (2014), 521-535. 1

[16] G. E. Kim, T. H. Kim, Mann and Ishikawa iterations with errors for non-Lipschitzian mappings in Banach spaces, Comput. Math. Appl., 42 (2001), 1565-1570. 1

[17] W. A. Kirk, B. Panyanak, A concept of convergence in geodesic spaces, Nonlinear Anal., 68 (2008), 3689-3696. 1

[18] W. R. Mann, Mean value methods in iteration, Proc. Amer. Math. Soc., 4 (1953), 506-610. 1

[19] B. E. Rhoades, Finding common fixed points of nonexpansive mappings by iteration, Bull. Austral. Math. Soc., 62 (2000), 307-310; Corrigendum, Bull. Austral. Math. Soc. 63 (2001), 345-346. 1, 4

[20] H. F. Senter, W. G. Dotson Jr., Approximating fixed points of nonexpansive mappings, Proc. Amer. Math. Soc., 44 (1974), 375-380. 2

[21] K.-K. Tan, H.-K. Xu, Approximating fixed points of nonexpansive mappings by the Ishikawa iteration process, J. Math. Anal. Appl., 178 (1993), 301-308. 1, 1.2

[22] I. Uddin, J. J. Nieto, J. Ali, One-step iteration scheme for multivalued nonexpansive mappings in CAT(0) spaces, Mediterr. J. Math., 13 (2016), 1211-1225. 1

[23] H. Y. Zhou, Y. J. Cho, S. M. Kang, A new iterative algorithm for approximating common fixed points for asymptotically nonexpansive mappings, Fixed Point Theory Appl., 2007 (2007), 10 pages. 2 